\title{
Acute Surgery vs. Non-union Surgery of Displaced Midshaft Clavicle Fractures: A Case-control Study
}

\author{
Michael Marsalli ${ }^{1,2}$, José T. Rojas ${ }^{3}$, Maximiliano Barahona ${ }^{4}$ \\ 1. Orthopaedic Department, Clínica Universidad De Los Andes, Santiago, CHL 2. Orthopaedic Department, Hospital Del \\ Trabajador, Santiago, CHL 3. Orthopaedic Department, Hospital San José, Santiago, CHL 4. Orthopaedic Department, \\ Hospital Clinico Universidad De Chile, Santiago, CHL
}

Corresponding author: Michael Marsalli, michaelmarsalli@gmail.com

\section{Abstract \\ Introduction}

There is a lack of information about the results of surgical treatment and complications in midshaft clavicle fracture non-unions. Our hypothesis was that there is no difference in functional outcomes between the surgical treatment of an acute displaced middle-third clavicle fracture and the surgical treatment of a chronic symptomatic non-union of a displaced middle-third clavicle fracture.

\section{Methods}

This was a case-control study. Fourteen cases were considered with a displaced midshaft clavicle fracture, initially treated non-surgically, but which developed symptomatic non-union and required surgical treatment. The control group was a cohort of 18 patients with a displaced midshaft clavicle fracture, who had surgical treatment in an acute setting ( $<3$ weeks). Our cases had a median follow-up of 77 months and were retrospectively analyzed. All those in the control group had a 12-month prospective follow-up evaluation. The variables measured were Constant score, time to discharge to work, and bone union rate.

\section{Results}

The median Constant score at final follow-up for surgically treated non-unions was 87.5 (control group 84.5, $\mathrm{p}>0.05$ ). The median time to complete return to work was 3.2 months in the control group and 9.7 months in the case group $(\mathrm{p}=0.001)$. Hundred percent of those patients who were initially treated with surgery had bone union without other treatment. Two out of 14 cases required a second surgery with a plate and bone graft to achieve bone union.

\section{Conclusion}

Symptoms from displaced midshaft clavicular fracture non-unions are due to related pain and dysfunctional deficits that result from displacement and shortening. According to our study, patients with a

Received 08/01/2019

Review began 08/06/2019 Review ended 08/21/2019 Published 08/25/2019

\section{() Copyright 2019}

Marsalli et al. This is an open access article distributed under the terms of the Creative Commons Attribution License CC-BY 3.0., which permits unrestricted use, distribution, and reproduction in any medium, provided the original author and source are credited. compared to patients treated in an acute setting for a displaced midshaft clavicle fracture. The median time to discharge and return to work was more than doubled in the non-union surgery group.

Categories: Other, Trauma

Keywords: clavicle fracture, clavicle non-union, clavicle surgical treatment, clavicle non-union surgery, midshaft clavicular fractures, clavicle treatment

\section{Introduction}

Displacement is probably the main risk factor for middle-third clavicle fractures to develop a nonunion, which has created a trend in the last five years towards their surgical treatment [1].

This trend results from the positive results in the two main objectives of this treatment. One, reducing the risk of the non-union of displaced midshaft clavicle fractures, where an odds ratio (OR) of 0.22 was reported for surgical treatment in systematic reviews or an overall $1.4 \%$ rate of non-union as compared with $14.5 \%$ for non-surgical treatment [2-3]. Also, the Constant score was demonstrated to be higher after one year of surgically treated displaced midshaft fractures [4-5]. This was validated in a study on patients with workers' compensation, who had type $2 \mathrm{~b}$ of Robinson's classification, in which surgical treatment with plate and screws had a higher Constant score after a year, an earlier return to work, and a lower rate of non-union (as compared to those with non-surgical treatment) [6-7].

Even with these results, we cannot recommend surgical treatment of displaced middle-third clavicle fractures for all patients. The number needed to treat (NNT) to prevent one non-union has been reported from 4.8 to as high as 10.3 and 18.5 for surgical treatment [2,8-9]. Among the arguments against 


\section{Cureus}

surgery is an elevated rate of reoperation, which is largely associated with symptoms related to plate use [10]. Other reported complications are infections of the surgical wound as well as transient neurological symptoms [11].

Questions about the cost-effectiveness of surgical treatment have been added to the discussion, which addresses the advantages and disadvantages of surgical and non-surgical treatment [1213]. When patients are provided with the proper information, many are concerned if after non-surgical treatment, they develop a symptomatic non-union that still requires surgery, the final results will be as good as if we opted for surgical treatment from the beginning. There is a lack of information about the functional results and complications in midshaft clavicle fractures non-unions. In a recent study, $60 \%$ of patients that developed a non-union required a secondary operation and the total reported complications of surgical treatment in this group has been higher than in acute fractures $[8,14]$.

Non-union surgical treatment results are important information to counsel patients with a displaced middle-third clavicle fracture. This study's main objective was to compare the functional outcomes of patients with acute surgical treatment of a displaced middle-third clavicle fracture vs. patients who were surgically treated for a symptomatic non-union of a displaced middle-third clavicle fracture. Secondary objectives were to evaluate the total time out of work with each treatment and the union rate of both groups.

Our working hypothesis was that there is no difference in functional outcomes between the surgical treatment of an acute displaced middle-third clavicle fracture and the non-union surgical treatment of a displaced middle-third clavicle fracture. However, acute surgical treatment tends to lead to a patient's earlier return to work.

\section{Materials And Methods}

This was a case-controlled study; the cases that were considered were of consecutive patients with a displaced midshaft clavicle fracture (Robinson $2 \mathrm{~b}$ ), initially treated non-surgically but that developed a symptomatic non-union and required surgical treatment between 2012 and 2014 (Figure 1). Initial treatment considered three weeks of shoulder immobilization and physiotherapy. Symptomatic non-union treatment was considered in patients with at least four months of follow-up, as well as without X-ray evidence of bone union and persistent pain symptoms. The control group was a prospective cohort of consecutive patients with a displaced midshaft clavicle fracture, who had surgical treatment in an acute setting ( $<3$ weeks).

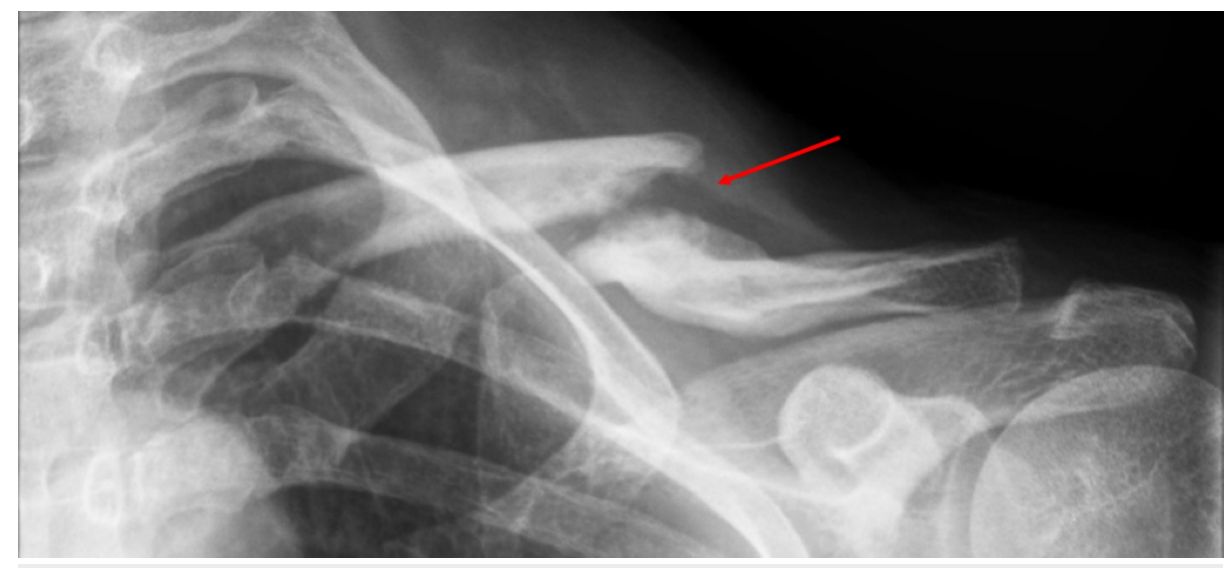

FIGURE 1: X-Ray example of a midshaft clavicle fracture non-union

Red arrow: non-union

The cases did not receive previous treatment for non-union issues until surgery. Both groups were surgically treated with open surgery and osteosynthesis (OTS), which included plates and screws. An iliac crest bone graft was used in the non-union group.

The inclusion criteria for both groups were:

1. Displaced midshaft clavicle fractures (Robinson $2 b$ )

2. Surgical treatment, including open treatment and OTS

3. A CT scan during follow-up for bone union evaluation 


\section{Cureus}

4. Functional evaluation at least after 12 months of follow-up

The exclusion criteria were:

1. Medial or lateral clavicle fractures

2. Associated vascular or neurologic injury

3. Open fractures

4. Associated ipsilateral fractures

The variables measured included: (1) Time to discharge for return to work, measured in months; (2) Bone union confirmed by CT scan; (3) Functional results measured with the Constant score [15]. A Kaplan-Meier analysis (Log-Rank test) was done to measure the time to discharge and the return to work. A median difference test for independent variables was also done, which considered a significant difference to be $\mathrm{p}$ value $\leqslant 0.05$. For all tests, STATA v 11.2 software was used (StataCorp LP, TX, USA).

\section{Results}

A total of 17 consecutive patients went to surgical treatment for a symptomatic non-union of a displaced middle-third clavicle fracture from years 2012 to 2014. Of them, 14 patients completed at least one-year follow-up, had a CT scan during follow-up, and went through a functional evaluation. The median time to surgery since the initial trauma of the non-union group was 5.2 months (4-15). The control group was a consecutive cohort of 18 patients, surgically treated for a displaced midshaft clavicle fracture between 2010 and 2012. Both groups included only patients with labor accidents treated in our hospital, who were under the working accidents compensation national law.

Our cases had a median follow-up of 77 months (range: 13 to 91). All those in the control group had a 12 month follow-up evaluation. The description of both groups can be observed in Table 1 .

\begin{tabular}{|c|c|c|c|}
\hline & Non-union surgery group (Cases) & Acute surgery group (Control) & P (test) \\
\hline Female & 7 & 2 & \\
\hline Men & 7 & 16 & 0.02 (Fisher) \\
\hline Age & $44.92( \pm 12.91)$ & $36( \pm 12.91)$ & 0.20 (Wilcoxon) \\
\hline Fracture type 2B1 & 9 & 8 & \\
\hline Fracture type 2B2 & 5 & 10 & 0.23 (Fisher) \\
\hline
\end{tabular}

TABLE 1: Cases and control group comparison

The median Constant score at final follow-up for surgically treated non-unions was 87.5 and for the control group, it was 84.5 ( $p>0.05$ ). A detailed Constant score distribution and comparison between groups can be observed in Figure 2. 


\section{Cureus}

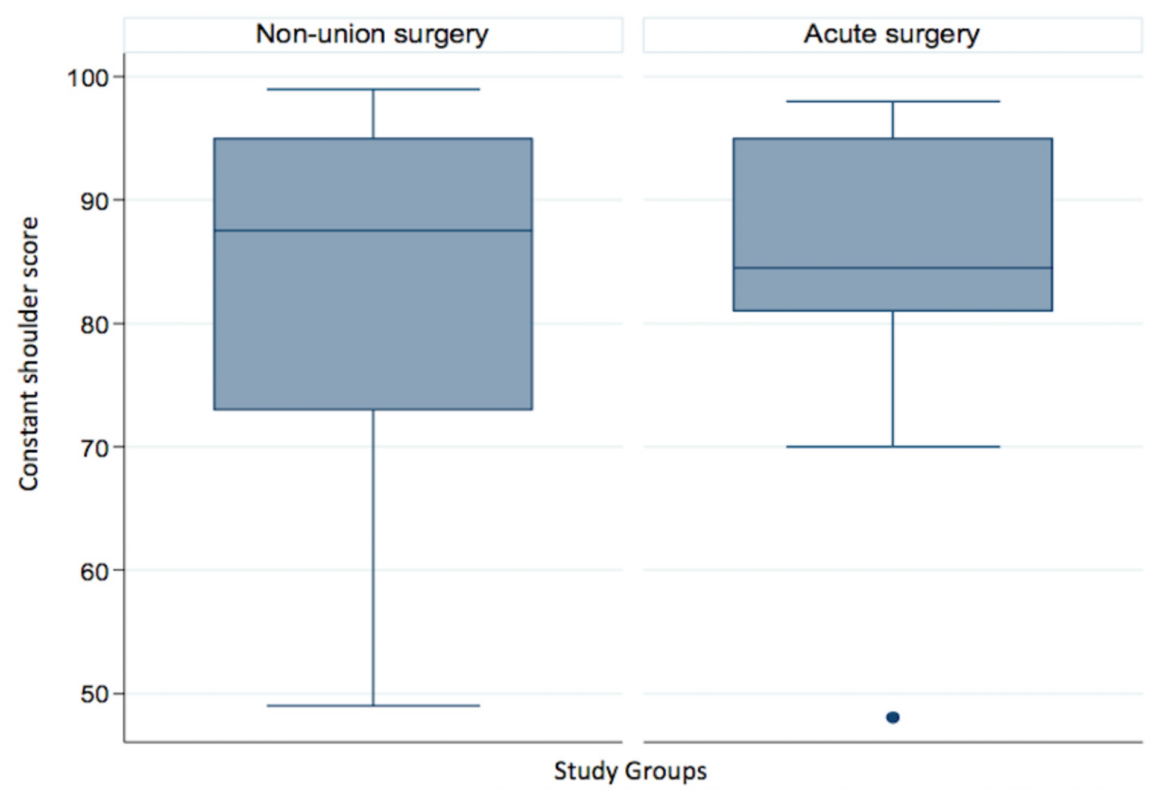

FIGURE 2: Constant score comparison between both study groups

The median time to complete return to work since the injury date was 3.2 months in the control group and 9.7 months in the case group $(\mathrm{p}=0.001)$, all being discharged from seven to 12 months after the fracture date, as seen in Figure 3. The median time to complete return to work since surgery in the non-union group was 4.9 months $(2.4-7.6)$.

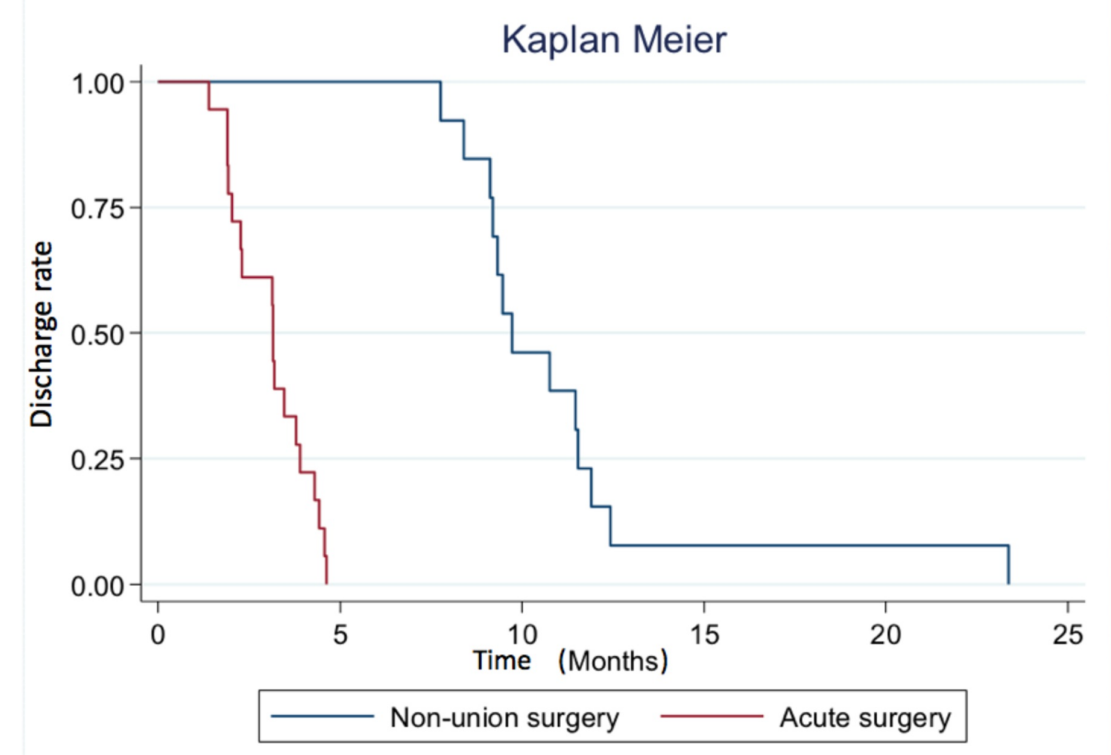

FIGURE 3: Median time to discharge to work

One hundred percent of those patients who were initially treated with surgery had bone union on CT scan without other treatment. However, two out of 14 cases required a second surgery with a plate and bone graft to achieve bone union. Both achieved bone union during follow-up after a second surgery. A CT scan of bone unions can be seen in Figure 4. 


\section{Cureus}

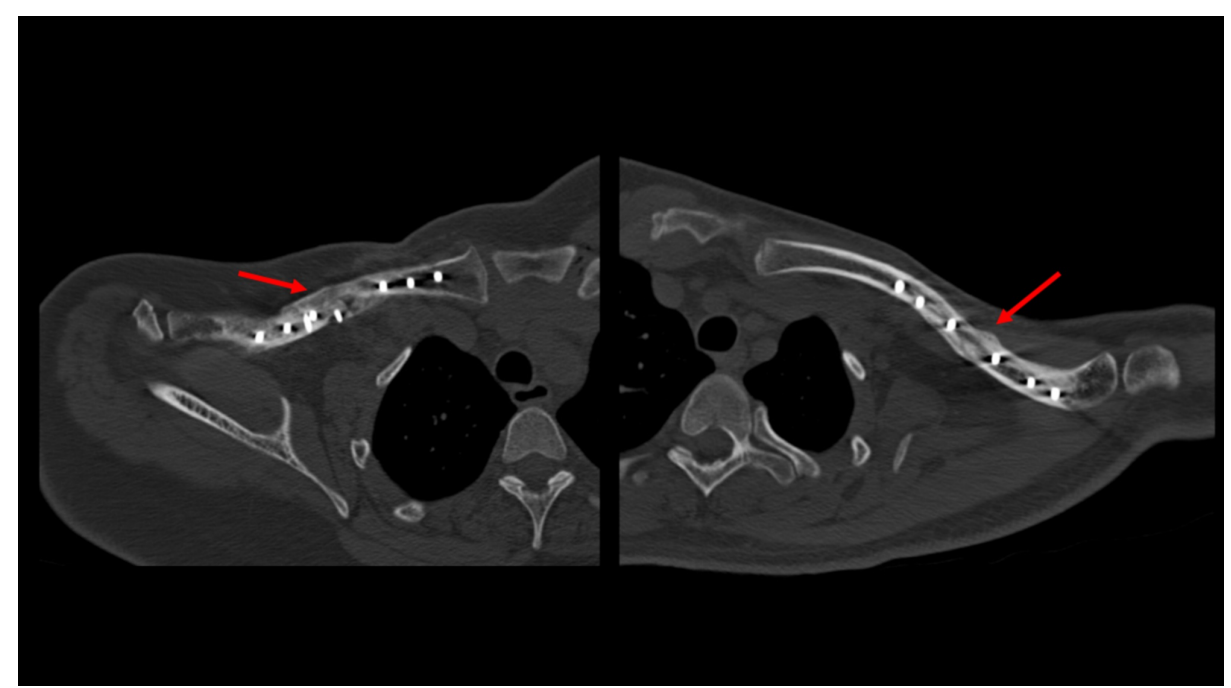

FIGURE 4: CT scans and bone union achieved after surgery

СT: computed tomography

Red arrow: signs of bone union

One patient in the acute surgical treatment group required a second surgery to remove a symptomatic plate. Both groups did not develop complications as superficial or deep infections, wound dehiscence, neurological deficits, or vascular injuries.

\section{Discussion}

Mckee et al. reported, in a group of 30 patients with a displaced midshaft clavicle fracture with nonoperative treatment, less strength (67\% vs. $82 \%$ of the contralateral shoulder) and an average Constant score of 71 with a Disabilities of the Arm, Shoulder, and Hand (DASH) score of 24.6, showing a functional deficit in these patients [16].

Symptoms from a displaced non-union midshaft clavicular fracture are due mainly to related pain from nonunion problems but also from dysfunctional deficits that may result from displacement and shortening. It has been previously described that the functional impairment of these last few factors may be corrected with a later surgery [17].

In our results, Constant scores were similar at the end of the patients' follow-up between those treated with surgery in the acute setting and those operated on later with a non-union ( 84.5 vs. $87.5, p=>0.05$ ). However, surgical treatment in the non-union group showed a Constant score with wide dispersion. This prompted us to think that positive results might be less predictable than displaced midshaft clavicular fractures with surgical treatment in the acute setting.

These results differed from those reported by Potter et al. [18], with a statistically significant difference in the Constant score in favor of acute surgery ( $95 \mathrm{vs.} 89 \mathrm{p}=0.02$ ). Conversely, the median difference of 6 points may be clinically irrelevant [19-21]. They did not find any difference in the DASH score, patient satisfaction, or absolute strength. However, the non-union surgical treatment group had lower resistance strength at the end of the follow-up.

In a recent study by McKnight et al,, 209 patients undergoing surgical treatment for non-union had a higher rate of total complications as compared with the acute fracture group ( $5.26 \%$ vs. $2.28 \%$; $=.034)$, a more than two-fold increased risk of any postsurgical complication (OR, 2.29 (95\% CI, 1.05-5.00); $\mathrm{p}=.037$ ) and $>$ three-fold increased risk of a wound complication (OR, 3.22 (95\% CI, 1.02-10.20); $=.046$ ) compared with acute fractures [14].

There was a significant difference in the median time to discharge to return to work between our study group ( 9.7 months) and the control group (3.2 months). This may be of interest in a workers' compensation population under labor insurance coverage and should be included in any cost-effective analysis. All patients with acute surgery were discharged for return to work before five months; however, our non-union surgery group required at least seven months from the initial trauma. A similar trend was observed in a group of 11 patients who went through a non-union surgery, where it took them more time to return to functional activities than patients surgically treated in the acute setting, but a similar single assessment numerical 
We achieved bone union in all patients with acute surgery. Two patients in the study group had a non-union and plate loosening during follow-up. They both required another surgery with a plate and bone autograft, and they finally achieved bone union after one year of follow-up.

In this case-controlled study, the non-union surgical group's functional results were like previously published results in an acute surgery setting, even though our study included patients with labor compensation [3-5,23].

This study is limited by the retrospective analysis of the non-union surgical group. Also, the small numbers of both groups and a 1:1 matching process limited the statistical analysis. Both groups did not match on gender and were not matched in other factors that may contribute to results as smoking status, although these factors have only been identified as risk factors for non-union in displaced middle-third clavicle fractures treated conservatively. The strength is the median follow-up of the non-union surgically treated group, being the longest one reported with functional results in the literature.

More prognostic studies about clavicle fracture non-union surgery are needed to advise patients whether surgical treatment is recommended for their fracture in the acute setting and what to expect if they need surgery for a non-union. Ideally, they should be high-quality prospective cohort studies, with patients enrolled at the same time point in the disease.

\section{Conclusions}

As actual evidence does not support surgical treatment for all displaced midshaft clavicle fractures, we should know the functional results expected for those patients that developed a symptomatic non-union and needed surgical treatment. According to our study, patients with a displaced midshaft clavicle non-union fracture who needed surgery achieved similar functional results as compared to patients treated in an acute setting for a displaced midshaft clavicle fracture. Despite these results, the median time to discharge and return to work were more than doubled in the non-union surgery group.

\section{Additional Information}

\section{Disclosures}

Human subjects: Consent was obtained by all participants in this study. Scientific Ethics Committee Hospital del Trabajador issued approval N/A. April 27, 2015 The ethics committee of Hospital del Trabajador (Santiago, Chile), took knowledge and ruled that this research does not raise objections of ethical nature. It was signed by Dr. Octavio Reyes (Hospital Director) and Dr. René Muga (ethics committee president). Authors have a printed certificate. Animal subjects: All authors have confirmed that this study did not involve animal subjects or tissue. Conflicts of interest: In compliance with the ICMJE uniform disclosure form, all authors declare the following: Payment/services info: All authors have declared that no financial support was received from any organization for the submitted work. Financial relationships: All authors have declared that they have no financial relationships at present or within the previous three years with any organizations that might have an interest in the submitted work. Other relationships: All authors have declared that there are no other relationships or activities that could appear to have influenced the submitted work.

\section{References}

1. Zlowodzki M, Zelle BA, Cole PA, JerayK, McKee MD: Treatment of acute midshaft clavicle fractures: systematic review of 2144 fractures: on behalf of Evidence-Based Orthopaedic Trauma Working Group. J Orthop Trauma. 2005, 19:504-507.

2. OrthoEvidencereview: operative vs nonoperative treatment for displaced clavicle fractures . (2015). http://myorthoevidence.com/ace/4862/orthoevidence-review-operative-vs-nonoperative-treatment-fordisplaced-clavicle-f....

3. McKee RC, Whelan DB, Schemitsch EH, McKee MD: Operative versus nonoperative care of displaced midshaft clavicular fractures: a meta-analysis of randomized clinical trials. J Bone Joint Surg Am. 2012, 94:675-684. 10.2106/JBJS.J.01364

4. Rehn CH, Kirkegaard M, Viberg B, Larsen MS: Operative versus nonoperative treatment of displaced midshaft clavicle fractures in adults: a systematic review. Eur J Orthop Surg Traumatol. 2014, 24:1047-1053. 10.1007/s00590-013-1370-3

5. Robinson CM, Goudie EB, Murray IR, et al.: Open reduction and plate fixation versus nonoperative treatment for displaced midshaft clavicular fractures: a multicenter, randomized, controlled trial. J Bone Joint Surg Am. 2013, 95:1576-1684. 10.2106/JBJS.L.00307

6. Melean PA, Zuniga A, Marsalli M, Fritis NA, Cook ER, Zilleruelo M, Alvarez C: Surgical treatment of displaced middle-third clavicular fractures: a prospective, randomized trial in a working compensation population. J Shoulder Elbow Surg. 2015, 24:587-592. 10.1016/j.jse.2014.11.041

7. Robinson CM: Fractures of the clavicle in the adult epidemiology and classification . J Bone Joint Surg Br. 1998, 80:476-484.

8. Woltz S, Stegeman SA, Krijnen P, et al.: Plate fixation compared with nonoperative treatment for displaced 
midshaft clavicular fractures. J Bone Joint Surg Am. 2017, 99:106-112. 10.2106/JBJS.15.01394

9. Jenkins PJ, Brooksbank AJ: Surgical treatment of displaced middle-third clavicular fractures: a prospective, randomized trial in a working compensation population. J Shoulder Elbow Surg. 2015, 24:320-321. 10.1016/j.jse.2015.07.021

10. Schemitsch LA, Schemitsch EH, Kuzyk P, McKee M: Prognostic factors for reoperation after plate fixation of the midshaft clavicle. J Orthop Trauma. 2015, 29:533-537. 10.1097/BOT.0000000000000331

11. Wijdicks FJ, Van der Meijden OA, Millett PJ, Verleisdonk EJ, Houwert RM: Systematic review of the complications of plate fixation of clavicle fractures. Arch Orthop Trauma Surg. 2012, 132:617-25. 10.1007/s00402-011-1456-5

12. Pearson AM, Tosteson AN, Koval KJ, et al.: Is surgery for displaced, midshaft clavicle fractures in adults cost-effective? Results based on a multicenter randomized, controlled trial. J Orthop Trauma. 2010, 24:426433. 10.1097/BOT.0b013e3181c3e505

13. Walton B, Meijer K, Melancon K, Hartman M: A cost analysis of internal fixation versus nonoperative treatment in adult midshaft clavicle fractures using multiple randomized controlled trials. J Orthop Trauma. 2015, 29:173-180. 10.1097/BOT.0000000000000225

14. McKnight B, Heckmann N, Hill JR, Pannell WC, Mostofi A, Omid R, Hatch GFR III: Surgical management of midshaft clavicle nonunions is associated with a higher rate of short-term complications compared with acute fractures. J Shoulder Elbow Surg. 2016, 25:1412-1417. 10.1016/j.jse.2016.01.028

15. Constant CR, Murley AH: A clinical method of functional assessment of the shoulder . Clin Orthop Relat Res. 1987, 214:160-164. 10.1097/00003086-198701000-00023

16. McKee MD, Pedersen EM, Jones C, et al.: Deficits following nonoperative treatment of displaced midshaft clavicular fractures. J Bone Joint Surg Am. 2006, 88:35-40.

17. McKee MD, Wild LM, Schemitsch EH: Midshaft malunions of the clavicle . J Bone Joint Surg. 2003, 85:790797.

18. Potter JM, Jones C, Wild LM, Schemitsch EH, McKee MD: Does delay matter? The restoration of objectively measured shoulder strength and patient-oriented outcome after immediate fixation versus delayed reconstruction of displaced midshaft fractures of the clavicle. J Shoulder Elbow Surg. 2007, 16:514-518. 10.1016/j.jse.2007.01.001

19. Henseler JF, Kolk A, van der Zwaal P, Nagels J, Vliet Vlieland TPV, Nelissen RG: The minimal detectable change of the Constant score in impingement, full-thickness tears, and massive rotator cuff tears. J Shoulder Elbow Surg. 2015, 24:376-81. 10.1016/j.jse.2014.07.003

20. Kukkonen J, Kauko T, Vahlberg T, Joukainen A, Äärimaa V: Investigating minimal clinically important difference for Constant score in patients undergoing rotator cuff surgery. J Shoulder Elbow Surg. 2013, 22:1650-1655. 10.1016/j.jse.2013.05.002

21. Yian EH, Ramappa AJ, Arneberg O, Gerber C: The constant score in normal shoulders . J Shoulder Elbow Surg. 2005, 14:128-133. 10.1016/j.jse.2004.07.003

22. Lädermann A, Abrassart S, Denard PJ, Tirefort J, Nowak A, Schwitzguebel AJ: Functional recovery following early mobilization after middle third clavicle osteosynthesis for acute fractures or nonunion: a case-control study. Orthop Traumatol Surg Res. 2017, 103:885-889. 10.1016/j.otsr.2017.03.021

23. Mirzatolooei F: Comparison between operative and nonoperative treatment methods in the management of comminuted fractures of the clavicle. Acta Orthop Traumatol Turc. 2011, 45:34-40.

10.3944/AOTT.2011.2431 